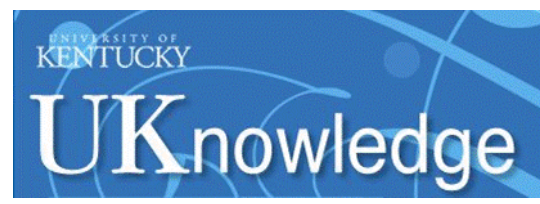

University of Kentucky

UKnowledge

1986

\title{
Dietary Characteristics of Hyperactive and Control Boys
}

\author{
Mark L. Wolraich \\ University of lowa \\ Phyllis J. Stumbo \\ University of lowa \\ Richard Milich \\ University of Kentucky, richard.milich@uky.edu \\ Catherine Chenard \\ University of lowa \\ Frederick Schultz \\ University of lowa
}

Follow this and additional works at: https://uknowledge.uky.edu/psychology_facpub

Part of the Clinical Psychology Commons

Right click to open a feedback form in a new tab to let us know how this document benefits you.

\section{Repository Citation}

Wolraich, Mark L.; Stumbo, Phyllis J.; Milich, Richard; Chenard, Catherine; and Schultz, Frederick, "Dietary Characteristics of Hyperactive and Control Boys" (1986). Psychology Faculty Publications. 59.

https://uknowledge.uky.edu/psychology_facpub/59

This Article is brought to you for free and open access by the Psychology at UKnowledge. It has been accepted for inclusion in Psychology Faculty Publications by an authorized administrator of UKnowledge. For more information, please contact UKnowledge@lsv.uky.edu. 


\section{Dietary Characteristics of Hyperactive and Control Boys}




\section{Dietary characteristics of hyperactive and control boys ${ }^{1}$}

Mark L. Wolraich, M.D., Phyllis J. Stumbo, Ph.D., R.D., Richard Milch, Ph.D., Catherine Chenard, R.D., and Frederick Schultz, M.D.

Division of Developmental Disabilities, Department of Pediatrics, University Hospital School, and Clinical Research Center, University of lowa, lowa City

The purpose of this study was to examine the relationship between dietary habits and behavioral problems in hyperactive boys and to determine how successful parents are in maintaining their children on sugar-free diets. The mothers of 32 hyperactive boys aged 7 to 12 years and 26 matched controls completed 3-day diet records and food frequency interviews. The hyperactive boys were also evaluated in a playroom for impulsivity, compliance, attention, motor activity, memory, and learning. No differences were found in any of the measures of dietary content between the hyperactive and control groups. The only significant differences between those two groups were a lower socioeconomic status and a greater number of parents attempting sugar-restricted diets in the hyperactive group. Boys on sugar-restricted diets had only one significant dietary difference from those not restricted. Correlations between the information obtained in food frequency interviews and in 3-day diet histories were not significant $(r=.06$ to .33 ) for the hyperactive group, but the food frequency interviews were significant for the control group ( $r=.41$ to .47). Four behavioral variables showed significant partial correlations with reported sugar intake. Overall, the results demonstrated that the diets of a group of hyperactive boys were similar to those of a control group. There appeared to be little difference between the diets of the families that attempted to restrict sugar and those that did not.

Considerable interest has arisen lately in the possible role that sugar may play in adversely affecting children's behavior. Many parents, especially those with hyperac-

This study was supported in part by Grant No. SA-7-364/83 from Sugar Associates, Inc., and in part by Grant No. RR59 from the General Clinical Research Center Program, Division of Research Resources, National Institutes of Health, Bethesda, Maryland. tive children, have become interested in restricting their children's intake of refined sugar in an attempt to improve their behavior. However, there is still little empirical evidence supporting a relationship between sugar intake and behavioral difficulties (1). The results of two recent studies (2) seriously challenge the belief that such a relationship exists.

Although the initial investigations have not revealed any effects of sugar on behavior, many issues still need to be explored to further disentangle real from presumed relationships when dietary effects on the behavior of children are discussed. The issues include, among others, an examination of the relationship between dietary habits and behavioral problems, with a special focus on hyperactivity.

A second issue relates to an examination of the dietary habits of hyperactive children to determine whether their consumption of refined sugar is different from that of normal children. A final question concerns how successfully parents who attempt it can maintain children on sugar-free diets. That point takes on added importance because, with the widespread use of sugar as a sweetener and a preservative, dietary restriction may be extremely difficult and perhaps not worth attempting without clearcut evidence of its benefits.

Dietary restriction would presumably be even more difficult for parents of hyperactive children because of the latter's poor impulse control, difficulty in following instructions, and frequent noncompliance (3).

To date, there has been an attempt in only one study (4) to address those issues systematically. The investigators collected 7-day diet records from 28 hyperactive and 26 control children ranging in age from 3 years, 9 months, to 7 years, 11 months. In addition, the investigators observed the children in a playroom setting and made observations of behaviors relating to destructive-aggressiveness, res:lessness, and quadrant changes (i.e., activity level). A comparison of the dietary records revealed no significant differences between the two groups of children in terms of the amount of sugar consumed. However, for the hyperac. tive group there was a significant and positive correlation between total sugar consumed and observations of both restlessness and destructive-aggressiveness. In contrast, for the control children there was a significant and positive correlation only between total sugar consumed and number of quadrant changes. 
Although the results of the Prinz et al. study (4) are intriguing, there is a major problem with the analyses that makes interpretation of the findings difficult, if not impossible. Specifically, the measure of sugar consumption employed was calculated on the basis of the weight of the food rather than the weight of the nutrients. Because foods may have markedly different densities, calculations based upon nutrient weight, the more accepted convention (5), might have produced dramatically different results. For example, if foods were heavy because of high water content (e.g., sweetened beverages), the assigned sugar value would have been greater if only the actual weight of the sugar were calculated. Similar problems were evident for the calculations of refined carbohydrate consumption employed by Prinz et al.

One purpose of the present study was to replicate the results of the Prinz et al. study, using the more conventional nutrient calculations. Specifically, comparisons were made of the diet records and food frequency reports of hyperactive and control children. Further, the diet records of the hyperactive children were compared with a variety of observation and laboratory learning measures to determine whether the relationships found by Prinz et al. held up. Observations were made only on the hyperactive group because of funding limitations. Finally, parents' attempts to, and success at, restricting their hyperactive children's sugar intake were examined. That was accomplished by comparing the dietary intakes of children whose parents stated they attempted or did not attempt to restrict sugar.

\section{Method}

\section{Subjects}

The subjects consisted of 32 hyperactive boys who were recruited through newspaper announcements for a sugar challenge study (2). The boys met selection criteria traditionally employed in drug or dietary studies of hyperactivity $(6,7)$. The criteria included: age 7 through 12 years, $1 Q$ greater than 85 , absence of any neurologic or severe psychiatric conditions, a history of overactivity and attentional problems as reported by parents and teachers, and a diagnosis of hyperactivity by the subject's local physician that was corroborated by one of the two developmental pediatricians involved in the research project. In addition, the boys had to receive a teacher rating of 15 or greater on the Conners Hyperkinesis Index. Evaluations given by both mothers and teachers using the Conners Hyperkinesis Index placed the boys at least two standard deviations above the mean in terms of perceived hyperactive symptomatology.

The 26 control subjects were also recruited through newspaper announcements. They were also boys between the ages of 7 and 12 years. They were screened to determine that they were in regular classes at their appropriate grade level, were not receiving resource room or remedial support, had no psychiatric diagnosis, had no serious chronic illness, and were not receiving mental health services.

\section{Diet records}

Assessing dietary sugar content is difficult because sugar is not clearly defined by the proponents of an association between sugar and hyperactive behavior (8) and data on the sugar content of food are not readily available. Reports generally implicate "refined" sweeteners. However, in a nutritional sense, there is no way to identify those compounds because the chemical structure of sugars in "refined foods" is the same as that found in whole foods. (For a discussion of the distinction between "whole" and "refined" foods, see Cleave's The Saccharin Disease [9].) Prinz et al. (4) attempted to address the problem by classifying the foods as sugar products, refined carbohydrates, and nutritional foods. This method required a common sense definition of refined sugar on the basis of food products but involved the previously discussed problems.

It was believed that a food grouping system using the generic term "sugar" to refer to all added caloric sweeteners would be the most appropriate approach. It was the authors' suspicion that most members of the public think of sucrose when they think of sugar, but sucrose accounts for only $67 \%$ of sweeteners sold in the United States (5). In addition, naturally occurring sugar content of foods varies, increasing in foods as they ripen and change during storage. Thus, data available on the sugar content of food can be only an approximation at best.

Use of a food grouping system to estimate added sugar content appeared to be the most reasonable method in view of the information constraints. A number representing grams of sugar was assigned to each food on the food frequency form on the basis of standard recipes and proportions for each food (10). Sugar content of food record items was approximated by grouping sweetened foods into one of five groups shown in Table 1. The nutritive composition of food record items was calculated using USDA nutritive data (11) and the appropriate percent from Table 1 applied to calculated carbohydrate content to estimate grams of sugar in each food.

Data on sugar intake were collected by two methods. First, a food record of total intake by the subjects was kept by each family. Three days were selected as an appropriate time span for this study. It was thought that parents

\begin{tabular}{|c|c|}
\hline $\begin{array}{c}\% \text { of } \\
\text { carbohydrate } \\
\text { as sweetener }\end{array}$ & food products \\
\hline 100 & $\begin{array}{l}\text { candy, gum, gelatin desserts, juice drinks, } \\
\text { marshmallows, soft drinks, popsicles, } \\
\text { sugar, honey, sherbet, lemonade, jelly, } \\
\text { syrup, frosting }\end{array}$ \\
\hline 75 & $\begin{array}{l}\text { cake with frosting, catsup, barbecue } \\
\text { sauce, ice cream, ice milk, pudding, } \\
\text { yogurt, sandwich cookie, sugar-coated } \\
\text { popcorn, chocolate-covered peanuts, } \\
\text { iced brownies, custard, cranberry juice } \\
\text { cocktail }\end{array}$ \\
\hline 50 & $\begin{array}{l}\text { brownies, cookies, doughnuts, syrup- } \\
\text { packed fruit, milk beverages, pies, } \\
\text { pastries, plain cake, sugar-coated } \\
\text { cereals, sweet rolls }\end{array}$ \\
\hline 25 & $\begin{array}{l}\text { pork and beans, graham crackers, granola } \\
\text { bars, muffins }\end{array}$ \\
\hline 0 & $\begin{array}{l}\text { bread products, salad dressing, lunch } \\
\text { meat }\end{array}$ \\
\hline
\end{tabular}


could easily comply with this request, and that length of time has been shown to be satisfactory for adults $(12,13)$. However, there are disadvantages to food records, the two primary ones being: (a) Recording activity tends to change behavior. (b) The food record measures intake only during a short time period, while customary intake varies greatly over a period of 28 days or longer (14).

In order to assess the intake of sugar over a longer period of time, a second method of data collection, the food frequency interview, has been suggested. A list of 17 common sweetened items covering a broad range of sweetened foods was developed. The boys and their mothers were independently interviewed to determine the frequency with which each item was eaten, as well as the quantity consumed. Respondents were allowed to answer in the time frame most appropriate for the food encountered (e.g., daily, weekly, monthly). All responses were converted to grams of sugar consumed daily.

Axelson and Csernus (15) have shown that method of frequency count to correspond to 24-hour diet recalls obtained from a large population, although in a second report the correlation of frequency counts to records kept for 1 week was poor (12). Because of the discrepancies, both diet records and food frequency interviews were collected. In addition, the food frequency interviews allowed information to be collected from the boys separate from their mothers.

\section{Behavioral observations}

The 32 hyperactive subjects were observed in a playroom setting. Also, they were given a battery of memory and attention tasks on two successive days as part of a study comparing the effects of sucrose and aspartame challenges (2). Observations were carried out in the Clinical Research Center at the University of lowa, with the children on sucrose-free diets on the challenge days. They received challenges with $1.75 \mathrm{gm} / \mathrm{kg}$ (mean dose $57.3 \mathrm{gm}$ ) of sucrose or an equivalent sweetness of aspartame (mean dose $197.3 \mathrm{mg}$ ). A counterbalanced order was employed to keep the subjects and researchers unaware of what each challenge contained. No significant differences were found on any of the measures between the two challenges. Because no differences were found between the two challenges, results for the 2 days were averaged together for the purpose of this analysis.

The variables included assessments of activity, impulsivity, and compliance during free play and academic tasks. Laboratory measures of attention and impulsivity were also obtained, including a continuous performance test, motor inhibition drawing tasks, and the Matching Familiar Figure Test. In addition, measures of learning were obtained, including a nonsense spelling task and a paired associate learning task. In all, 37 variables were examined. It was not possible to observe the control group under the same conditions. However, it is worth noting that the Prinz et al. study (4) found that most of the significant correlations appeared in data generated by the group of hyperactive children.

\section{Results}

Table 2 presents means and standard deviations for dietary content. Table 3 presents the weight, age, and socioeconomic status determined on the basis of the Hollingshead
Table 2, Sugar and other energy nutrients in diets of 32 hyperactive and 26 control boys

\begin{tabular}{lccc}
\hline \multicolumn{1}{c}{ diet records } & $\begin{array}{c}\text { hyperactive } \\
\text { boys }\end{array}$ & $\begin{array}{c}\text { control } \\
\text { boys }\end{array}$ & difference \\
\hline protein (gm) & $70 \pm 14^{*}$ & $74 \pm 16$ & NS \\
fat (gm) & $87 \pm 22$ & $80 \pm 22$ & NS \\
carbohydrate (gm) & $256 \pm 72$ & $272 \pm 51$ & NS \\
sugar (gm) & $79 \pm 50$ & $88 \pm 42$ & NS \\
total calories & $2,097 \pm 485$ & $2,094 \pm 369$ & NS \\
caloric need & $2,098 \pm 2152,193 \pm 264$ & NS \\
sugar (\% kcal) & $15 \pm 6$ & $17 \pm 7$ & NS \\
sugar (\% carbohydrate) & $30 \pm 1$ & $32 \pm 11$ & NS \\
carbohydrate/protein (gm) & $3.7 \pm 0.8$ & $3.8 \pm 0.9$ & NS \\
sugar (gm)/kg body weight & $2.4 \pm 1.5$ & $2.4 \pm 1.3$ & NS \\
food frequency & & & \\
$\quad$ sugar, gm/day, child report & $127 \pm 89$ & $108 \pm 59$ & NS \\
$\quad$ sugar, gm/day, parent report & $94 \pm 56$ & $100 \pm 52$ & NS \\
restricting sugar (\%) & 59 & 12 & $p<.001 \dagger$ \\
\hline *Mean \pm standard deviation. & & & \\
t $\chi^{2}=13.94$. & & & \\
\hline
\end{tabular}

Table 3. Characteristics of 32 hyperactive and 26 control boys

\begin{tabular}{lccc}
\hline \multicolumn{1}{c}{ characteristic } & $\begin{array}{c}\text { hyperactive } \\
\text { boys }\end{array}$ & $\begin{array}{c}\text { control } \\
\text { boys }\end{array}$ & difference \\
\hline age $(\mathrm{yr})$ & $10.2 \pm 1.5^{*}$ & $10.2 \pm 1.4$ & $\mathrm{NS}$ \\
weight $(\mathrm{kg})$ & $33.7 \pm 7.7$ & $37.1 \pm 9.5$ & $\mathrm{NS}$ \\
$\begin{array}{l}\text { socioeconomic status } \\
(1=\text { highest, } 5=\text { lowest })\end{array}$ & $3.3 \pm 0.8$ & $1.6 \pm 0.9$ & $p<.001$ \\
\hline *Mean \pm standard deviation. & & & \\
\hline
\end{tabular}

and Redlich criteria (16) for both the hyperactive and the control groups. Because there was a significant difference in socioeconomic status between the two groups, analyses of covariance were performed on the means with socioeconomic status as a covariant. Because of some missing socioeconomic status data, the sample for analysis consisted of 29 hyperactive boys and 24 control boys.

With socioeconomic status controlled for, there were no differences between the two groups in any of the dietary measures. The sample rank sum tests used by Wolraich et al. (2) were calculated for groups not normally distributed and also showed no differences between the two groups on any of the diet contents.

Means of dietary data for each nutrient were nearly identical for the two groups. Approximately half the calories from food records were derived from carbohydrates, with about $15 \%$ of total calories provided by refined sugar. Children reported a greater intake of foods containing sugar than was reported by the parents in their responses to the food frequency interview. This was significant for the hyperactive group $(t=2.13, p<.05)$ but not for the control group $(t=.32 \mathrm{NS})$.

There was a significant difference $\left(\chi^{2}=13.94, p<.001\right)$ between the proportion of parents of hyperactive children $(59.4 \%)$ and the porportion of parents of children in the control group (11.5\%) who stated they were restricting or had tried to restrict sugar. The means and standard deviations for diet content for those children on restricted 
Table 4. Sugar and other energy nutrients in diets of 32 hyperactive and 26 control boys on diets restricted or nonrestricted in sugar

\begin{tabular}{|lccc}
\hline \multicolumn{1}{c}{ diet records } & $\begin{array}{c}\text { sugar } \\
\text { restricted }\end{array}$ & $\begin{array}{c}\text { not } \\
\text { restricted }\end{array}$ & difference \\
\hline protein (gm) & $72 \pm 18^{*}$ & $72 \pm 13$ & $\mathrm{NS}$ \\
fat (gm) & $84 \pm 25$ & $83 \pm 22$ & $\mathrm{NS}$ \\
carbohydrate (gm) & $261 \pm 81$ & $264 \pm 51$ & $\mathrm{NS}$ \\
sugar (gm) & $78 \pm 58$ & $87 \pm 6$ & $\mathrm{NS}$ \\
total calories & $2,095 \pm 554$ & $2,096 \pm 349$ & $\mathrm{NS}$ \\
caloric need & $2,049 \pm 270$ & $2,134 \pm 227$ & $\mathrm{NS}$ \\
sugar (\% of kcal) & $14 \pm 7$ & $16 \pm 6$ & $\mathrm{NS}$ \\
sugar (\% of carbohydrate) & $28 \pm 13$ & $32 \pm 9$ & $p<.05$ \\
carbohydrate/protein (gm) & $3.7 \pm 0.9$ & $3.7 \pm 0.8$ & $\mathrm{NS}$ \\
sugar (gm)/kg body weight & $2.3 \pm 1.7$ & $2.5 \pm 1.2$ & $\mathrm{NS}$ \\
hyperactive (no.) & 19 & 13 & $p<.001$ \\
control (no.) & 3 & 23 & $\chi^{2}=13.94$ \\
\hline *Mean \pm standard deviation. & & & \\
\hline
\end{tabular}

Table 5. Correlation* of sugar intake as determined by food record and food frequency between parent and child and between food record and frequency interview

\begin{tabular}{|c|c|c|c|c|}
\hline \multirow[t]{2}{*}{$\begin{array}{l}\text { sugar consumption } \\
\text { calculated from }\end{array}$} & \multicolumn{2}{|c|}{$\begin{array}{l}\text { hyperactive } \\
\text { group }\end{array}$} & \multicolumn{2}{|c|}{$\begin{array}{l}\text { control } \\
\text { group }\end{array}$} \\
\hline & $r$ & $p$ & $\mathbf{r}$ & $p$ \\
\hline $\begin{array}{l}\text { diet record vs. } \\
\text { freq. interview, parent } \\
\text { diet record vs. }\end{array}$ & 0.33 & NS & 0.26 & NS \\
\hline $\begin{array}{l}\text { freq. interview, child } \\
\text { freq. interview, parent vs. }\end{array}$ & 0.06 & NS & 0.47 & 0.02 \\
\hline freq. interview, child & 0.32 & NS & 0.41 & 0.04 \\
\hline
\end{tabular}

Table 6. Significant partial correlations (controlling for age and socioeconomic status) between 37 behavioral and cognitive measurements and percent of carbohydrate as sugar

\begin{tabular}{lr}
\hline free-play behavioral measurements & \multicolumn{1}{c}{$\mathrm{r}$} \\
\hline ankle actometer & $0.39^{*}$ \\
grid crossing & $0.53^{*}$ \\
on-task & $-0.48^{*}$ \\
attention shifts & $0.42^{*}$ \\
\hline${ }^{*} p<0.05$ & \\
\hline
\end{tabular}

and nonrestricted sugar diets are shown in Table 4. No significant differences were found for any of the dietary parameters between those who stated that they restricted sugar and those who did not, with the exception that sugar comprised a significantly $(p<.05)$ smaller portion of the total carbohydrates in the restricted group. On the basis of the information reported in their diet records, only $47 \%$ of those parents who stated that they restrict sugar were actually able to limit their child's diet to $50 \mathrm{gm}$ or less of sugar per day.

Correlations of the data gathered by the three methods-the food frequency reports of the children, the frequency reports of their parents, and the diet record- are presented in Table 5. Spearman correlation coefficients were calculated to minimize the effect of outlying results, which reduced the linear correlation greatly.

There were nonsignificant correlations among all three measures for the hyperactive boys and their mothers, but significant correlations, in the range of 0.41 to 0.47 , emerged for control boys and their mothers on two of the three comparisons.

Table 6 presents the significant partial correlations (with age and socioeconomic status controlled for) between the 37 behavioral and cognitive variables and the ratio of sugar to total carbohydrates consumed by the hyperactive group. That parameter showed the greatest number of correlations. No significant correlations were found for any of the variables with total sugar consumption or the carbohydrate-to-protein ratio. The ratio of sugar to total calories showed significant correlations for two of the same measures as the sugar-to-carbohydrate ratio (grid crossing and on task behavior). The ratio of sugar to weight showed significant correlations for one of the same measures (grid crossing).

Although the number of significant correlations (4 of $37)$ between the variables and percent of carbohydrate consumed as sugar was not large, the correlations were all in the same direction. Free-play activity levels were higher, and off-task behaviors were increased in those children having a greater proportion of sugar in their diets.

\section{Discussion}

The present study found no differences in the dietary characteristics of hyperactive boys and a matched control group. These results are consistent with those obtained by Prinz et al. (4), although the nutrient levels were incorrectly calculated in the latter study. Further, the sugar intakes reported by the two groups in the present study are consistent with those presented for normative samples, when the latter are recalculated to reflect refined sugar only (17).

Not unexpectedly, more parents of hyperactive boys than parents of control boys reported attempting to restrict their children's sugar intake. Surprisingly, however, only one significant difference was found in the data for children whose families did or did not try to restrict sugar. That was in the percent of sugar comprising the total carbohydrate intake. The fact that 11 parameters were examined and none of the others was significantly different, suggests that major differences did not exist and the one parameter could have occurred by chance. Further, less than half of the restricters were able to limit their child's intake to $50 \mathrm{gm}$ or less of sugar per day. Those discouraging findings take on added importance because as many as $45 \%$ of pediatricians in a recent survey (18) reported recommending a restricted-sugar diet for their hyperactive patients. Further, Prinz (19) reported that attempting to impose such dietary restrictions may exacerbate already strained parent-child interactions. The challenge studies offer no support for such restricted diets, and the present study indicates that many parents cannot adhere to the recommendation successfully. Therefore, the role of dietary interventions needs to be carefully reevaluated to determine whether such interventions are helping or exacerbating the problem.

Several other important findings emerged from the 
present study. The boys in both groups tended to report higher intakes of sugar in their diets than their mothers, although the differences reached significance only for the hyperactive group. That may indicate either that the boys are eating more sugar products than the parents realize or that the reports of the hyperactive boys are less reliable.

Consistent with the results of Prinz et al. (4), several significant and positive correlations were found between increased symptomatic behavior and higher reported sugar intake. However, those findings need to be interpreted cautiously.

First, only 4 of the 37 behavioral measures exhibited significant correlations, and the ones obtained differ from those reported by Prinz et al. One could say that what is more impressive is the number that did not exhibit significant correlations.

Second, most studies using an intervention design to examine the relationship between sugar and behavior in children have not found significant effects (1). Thus, any correlation obtained between sugar intake and behavior is likely to suggest that the greater the level of hyperactivity, the more sugar consumed by the children, rather than that increased sugar consumption increases symptomatic behavior.

The results of the present study also have important implications for the collection of dietary data among special populations. Specifically, the frequency and diet history data collected from the mothers of the two groups did not significantly agree. However, even though the hyperactive group's mother-and-child reports did not significantly agree, the reports for the control group did. Discrepancies between food frequency interviews and dietary recalls have been reported, as was noted previously (15). Taken together, the results suggest that the information generated at least by the hyperactive group may be unreliable. Whether it is due to the lower educational levels of the mothers of the hyperactive boys, the attentional difficulties of the hyperactive boys, and/or problems with the methods of obtaining the information cannot be ascertained from the present study.

However, it is clear that further research is needed to clarify the relationship between type of subject and response to different types of dietary data collection methods. The results also point out the low reliability of historical dietary information and the need to use multiple sources of dietary information whenever possible.

\section{References}

(1) Milich, R., Lindgren, S., and Wolraich, M.: The behavioral effects of sugar: A comment on Buchanan. Am Psychol. In press.

(2) Wolraich, M.L., Milich, R., Stumbo, P., and Schultz, F.: The effects of sucrose ingestion on the behavior of hyperactive boys. J Pediatr 106:675, 1985.

(3) Barkley, R.: Hyperactive Children. New York: Guilford Press, 1981.

(4) Prinz, R.J., Roberts, W.A., and Hantman, E.: Dietary correlates of hyperactive behavior in children. J Consult Clin Psychol 48:760, 1980.

(5) Woteki, C.E., Welsh, S.O., Raper, N., and Marston, R.M.: Recent trends and levels of dietary sugars and other caloric sweeteners. In Reiser, S., ed.: Metabolic Effects of Utilizable Dietary Carbohydrates. New York: Marcel Dekker, 1982.

(6) Harley, J., Ray, R., Tomasi, L., Eichman, P., Mathews, C., Chun, R., Cleeland, C., and Trausman, E.: Hyperkinesis and food additives: Testing the Feingold hypothesis. Pediatrics 61:818, T978.

(7) Schain, R.J., and Reynard, C.L.: Observations on effects of a central stimulant drug (methylphenidate) in children with hyperactive behavior. Pediatrics $55: 709,1975$.

(8) Cott, A.: Treatment of learning disabilities. In Williams, R.J., and Kalita, D.K. eds.: A Physician's Handbook on Orthomolecular Medicine. New York: Pergamon Press, 1977.

(9) Cleave, T.L.: The Saccharine Disease. Bristol, England: John Wright and Sons Ltd., 1974.

(10) Handbook of Food Preparation. Washington, DC: American Home Economics Association, 1975.

(11) Adams, D.F., and Richardson, M.: Nutritive value of foods. USDA Home and Garden Bull No. 72, 1981

(12) Stuff, J.E., Garza, C., Smith, E.O., Nichols, B.L., and Montandon, C.M.: A comparison of dietary methods in nutritional studies. Am J Clin Nutr 37:300, 1983.

(13) Todd, K.S., Hudes, M., and Calloway, D.H.: Food intake measurement: Problems and approaches. Am J Clin Nutr 37:139, 1983.

(14) St. Jeor, S.T., Guthrie, H.A., and Jones, M. B.: Variability in nutrient intake in a 28-day period. J Am Diet Assoc 83:155, 1983.

(15) Axelson, J.M., and Csernus, M.M.: Reliability and validity of a food frequency checklist. J Am Diet Assoc 83:152, 1983.

(16) Hollingshead, A., and Redlich, F.: Social Class and Mental Illness. New York: John Wiley \& Sons, 1958.

(17) Morgan, K.J., and Zabick, M.E.: Amount and food sources of total sugar intake by children ages 5-12 years. Am J Clin Nutr 34:404, 1981.

(18) Bennett, F.C., and Sherman, R.: Management of childhood "hyperactivity" by primary care physicians. J Dev Behav Pediatr 4:88, 1983

(19) Prinz, R.J.: Personal communication, 1984 